\title{
Determining the Relationship between Resistivity, Water and Hydrocarbon Saturation of Rock Formation Using Composite Well Logs
}

\author{
Mamudu Afizu \\ Department of Physics, Federal College of Education (Technical), \\ P.M.B. 1013, Potiskum, Yobe State-Nigeria
}

\section{Doi:10.5901/ajis.2013.v2n13p119}

\begin{abstract}
Absract
This paper focuses on comparing the percentages of water and hydrocarbon saturation to the resistivity of formation of reservoirs in an oil well by using composite logs. The composite logs were obtained from Nigeria National petroleum co-operation (NNPC) Etete Benin branch Edo state. Eight reservoirs were considered from a well in Ambura field in Delta state. When the logs were interpreted a composite table containing values of resistivity, percentages of water and hydrocarbon saturation was produced. From the values obtained it was found that resistivity increases with hydrocarbon saturation and decreases with water saturation in each reservoir. A graph of resistivity against hydrocarbon saturation and resistivity against water saturation was plotted. In conclusion, suggestions and recommendations were made to promote further research work on the project.
\end{abstract}

Keywords: Resistivity, Rock, Formation, Water, Hydrocarbon

\section{Introduction}

A well log is a graph of depth in a well versus some characteristics or properties of the rock. Hydrocarbon is obtained in the pore space of a reservoir rock. The late George R. Pickett of the Colorado School of Mines once said that using well logs in oil and gas exploration was like hunting on a game preserve. However most people in the petroleum industry know that well logs plays a key role in oil and gas exploration and reservoir evaluation. When a well drilling is finished, a decision must be made as to whether to complete the well or plug and abandon it.

Well logs can be used to identify the best reservoirs. Well logs are used to make quantitative estimates of volume of hydrocarbon present in subsurface Earth formations. Well logs are obtained by moving various types of instruments having sensors therein along a wellbore drilled through the subsurface formations. Sensors in typical well log instruments make measurements of particular petrophysical properties of the surface formations, including, for example, electrical resistivity, acoustic velocity, density, natural gamma radiation, neutron porosity and dielectric constant, among others.

According to David F Allen 2009, a well longing method includes moving a longing instrument along a wellbore drilled through a laminated subsurface formation. The instrument includes a first sensing device for detecting a vertical resistivity and a horizontal resistivity in the formation and a second sensing device for determining a total porosity and an irreducible water saturation in the formation. Values of horizontal resistivity and vertical resistivity in the laminated formation are determined from measurement made by the first sensing device. Bound water saturation and total porosity of individual layers of the formation are determined from measurement made by the second sensing device. 
In rocks, saturation refers to fraction or percent of the pore space that is occupied by some fluid or hydrocarbon. If the pore spaces in a rock are completely full of water, we say they are $100 \%$ saturated. If the pore spaces have $40 \%$ of their volume occupied with hydrocarbon and the rest with water, there is obviously $60 \%$ water saturation in the pore system. The total fraction of both hydrocarbon and water is $100 \%$ or simply 1 if we are dealing in fractional parts instead of percentage

Resistivity of a well is a measure of the resistance a given volume of fluid in the well will offer to the flow of current. When the resistivity of a clear solution $\left(R_{0}\right)$ and the true resistivity $\left(R_{t}\right)$ are determined, the resistivity index is the ratio of $R_{t}$ to $R_{0}$. Most natural waters in rocks contain salts of various kinds. The majority of natural waters are conductive. The equation for the resistance of a one meter cube to current flow through two parallel faces can be written: Resistance of cube of water $=$ resistivity of water $*$ length / area. If length and area both equal 1, then: Resistance $(\mathrm{ohm})=\mathrm{RW}$ (ohm - meter) (resistivity of water).The resistance, in ohms, of a one meter cube of water is numerically equal to the resistivity of the water in ohm-meters. This is true for any material or combination of materials and is not restricted only to water.

Consider a one meter cube of rock that is $100 \%$ water saturated, that is, all the pores are filled with water. Resistivity of the cube may be written in terms of the current path length, area and resistivity. The concept of formation resistivity factor is one of the most important in petrophysical analysis. Formation resistivity factor is the ratio of the resistivity of $100 \%$ water saturated rock to the resistivity of the water with which it is saturated. F = Ro / RW .The resistivity of the current path is RW and the path length (Le1) is at least one meter, but probably longer. The area is proportional to porosity. Resistivity of a formation in a direction along the direction of the layers of the formation and the direction transverse to the layer direction are referred to as horizontal and vertical resistivities respectively.

\section{Literature Review}

Much work has been done to develop empirical relationships between water resistivity, porosity, and water saturation. G.E. Archie in 1942 showed with core samples, that formation resistivity factor, water resistivity and rock resistivity are related by the following expression over wide ranges of porosity: $F=$ Ro / RW ( $F=$ formation factor, Ro = resistivity of rock filled with water (ohm-m), $\mathrm{RW}=$ resistivity of water $(\mathrm{ohm}-\mathrm{m})$. Archie also stated that water saturation is related to the rock resistivity by the expression: $\mathrm{Sw}=(\mathrm{Ro} / \mathrm{Rt}) \wedge(1 / \mathrm{N}) . \mathrm{N}=$ saturation exponent (unitless), Ro = resistivity of rock filled with water (ohm-m), Rt = resistivity of rock filled with water and oil (ohm$\mathrm{m}), \mathrm{Sw}=$ water saturation (fractional)

A method for estimating hydrocarbon volume in a layered subsurface formation includes determining a vertical resistivity and horizontal resistivity in the formation. Values of horizontal resistivity and vertical resistivity of the formation are calculated based on the bound water saturation and total porosity for each layer and on an estimated irreducible bulk volume of water in each layer. The estimated values are compared to the determined horizontal resistivity and vertical resistivity. The estimated irreducible water saturation in each layer is adjusted and estimating the values is repeated until differences between the estimated values and the determined vertical and horizontal resistivity values fall below a selected threshold. The hydrocarbon volume is estimated from adjusted irreducible water saturation for each layer. (David F, Allen 2009).

According to Roland Chemali 2012, formation evaluation is performed based on deconvolution guided by microresistivity images. It involves interpreting the vertical and horizontal resistivity in terms of Vshale and hydrocarbon content. Method for estimating properties of fluid in rock formations at selected locations within a geologic basin includes generating an initial model of the basin. The model includes an output spatial distribution of at least rock formation, mineral composition, rock formation porosity, and composition of fluid in the rock formation porosity. (Soraya Betan court 2010). 
Electricity can pass through a formation only because of conductive water contained within the formation. Perfectly dry rocks are very seldom encountered in the subsurface. Water is in their pores or absorbed in their interstitial clay, therefore subsurface formations have finite, measurable resistivities. A raservior has a conducting part: salt water and a non- conducting part hydrocarbon. Conductivity is the reciprocal of resistivity. A substance with infinite resistivity has conductivity of zero and a substance with low resistivity has high conductivity. According to Archie 1942, the resistivity of the formation water, Rw is an instrisic property of the water and is a function of its salinity and temperature. The higher this variable, the more conductive is the water and the lower its resistivity. The ability of a rock to conduct electricity is due to the ions in its pore spaces.

With a large percentage of the world's known hydrocarbon reservoir located in carbonate reservoirs, the push to increase production has revealed a need to improve oil saturation calculation in carbonate transition zone. He discovered that carbonate transition zones exhibit resistivity and pressure gradient phenomena that respond like water zones to resistivity and pressure gradient measurement. Prasonjo and Y. Sallam (2006).

According to Ivan. S 2012 reservoir rocks hydrocarbon saturation calculation with resistivity log is substantially limited by information shortage about petro physical characteristics of reservoirs mineral components. The adaptive resistivity log data interpretation is forced to share in the effective pore volume. Petro physical assurance of this technique is relation between measured resistivity and changes in reservoir water holding capacity. It is necessary to specify three resistivity characteristics values. There are resistivity of the reservoir in case when all pore volume is filled with irreducible water, resistivity of water bearing reservoir and oil bearing reservoir with maximal available total porosity.

\section{Methodology}

In this paper reference was made particularly to resistivity log. Deep resistivity was considered because hydrocarbon was found there. The track had a scale of $(0.2$ to 2000$) \Omega \mathrm{m}$. The resistivity of clear solution of the rock was determined and the true resistivity was measured from the resistivity log. Six reservoirs were considered from the well and their resistivity indexes were computed. Water saturation of each reservoir was determined from the resistivity index. Assuming the total resistivity of the rock being $100 \%$, the hydrocarbon saturation was computed. The following mathematical expressions were considered.

Resistivity index $(\mathrm{I})=\mathrm{R} \mathrm{t} / \mathrm{R}_{0}$

Water saturation $\left(S_{w}\right)=1^{-1 / n} \%$

$\mathrm{N}=2$

Hydrocarbon saturation $\left(\mathrm{S}_{\mathrm{H}}\right)=\left(1-\mathrm{S}_{\mathrm{W}}\right) \%$

\section{Result}

A table comprises resistivity of rock formation, water saturation and hydrocarbon saturation

\begin{tabular}{lccc}
\hline $\begin{array}{l}\text { Reservoir } \\
(\mathrm{R})\end{array}$ & $\begin{array}{l}\text { Resistivity } \\
\text { of formation }\left(\mathrm{R}_{\mathrm{t}}\right) \Omega \mathrm{m}\end{array}$ & $\begin{array}{l}\text { Water } \\
\text { saturation }\left(\mathrm{S}_{\mathrm{w}}\right) \%\end{array}$ & $\begin{array}{c}\text { Hydrocarbon } \\
\text { saturation }\left(\mathrm{s}_{\mathrm{h}}\right) \%\end{array}$ \\
\hline $\mathrm{R}_{1}$ & 40.2 & 27.3 & 72.7 \\
$\mathrm{R} 2$ & 30.2 & 31.5 & 68.5 \\
$\mathrm{R} 3$ & 05.2 & 70.0 & 30.0 \\
$\mathrm{R} 4$ & 20.2 & 38.6 & 61.4 \\
$\mathrm{R} 5$ & 66.9 & 13.4 & 86.6 \\
$\mathrm{R} 6$ & 04.2 & 76.0 & 24.0 \\
\hline
\end{tabular}

\section{Discussion of Result}

From the result gotten from the research work it was discovered that the resistivity of formation of 
a rock increases with the hydrocarbon saturation and decreases with the water saturation. Reservoir R5 had the highest resistivity of $66.9 \Omega \mathrm{m}$ and hydrocarbon saturation of $86.6 \%$ but, the same reservoir had water saturation of $13.4 \%$ as the lowest. R6 had the lowest resistivity of $4.2 \Omega \mathrm{m}$ and the lowest hydrocarbon saturation of $31.0 \%$ and $69.0 \%$ of water saturation as the highest.

\section{Conclussion}

It was discovered by the researcher that increase in formation resistivity signifies increase in hydrocarbon saturation and decrease in formation resistivity signifies decrease in water saturation. From the research result it was very easy to determine the percentage of water and the hydrocarbon saturation of a rock when the resistivity of the formation was known.

\section{Recommendation}

* Actual volume of hydrocarbon saturation and water saturation of a rock formation should be determine using the project

* Relationship between porosity, hydrocarbon and water saturation should be research on

* More reservoirs should be considered to confirm the authenticity of the research

* Other fields and wells should be considered for further research to ensure the truthfulness of the method

* Relationship between formation resistivity factor and porosity should be research on

Graph of resistivity against water saturation.

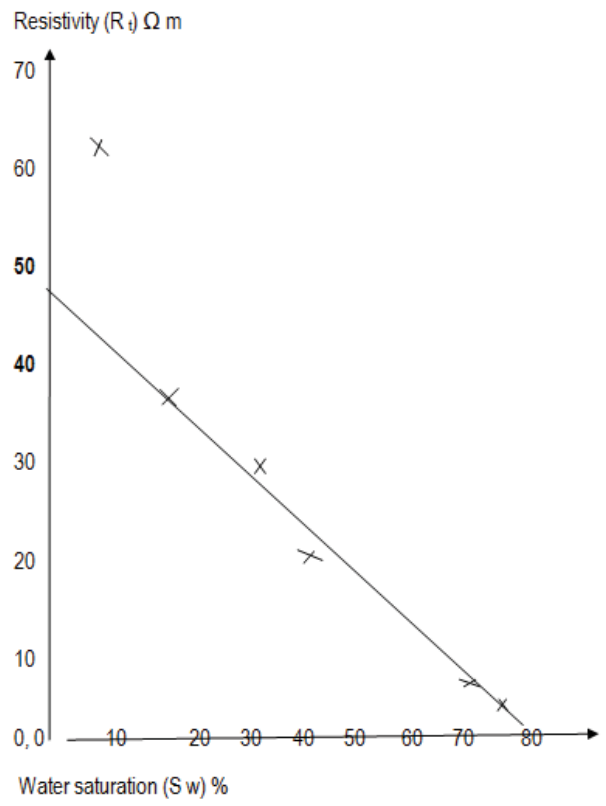

Graph of formation resistivity $(\mathrm{R} \mathrm{t})$ against hydrocarbon saturation $\left(\mathrm{S}_{H}\right) \%$ 


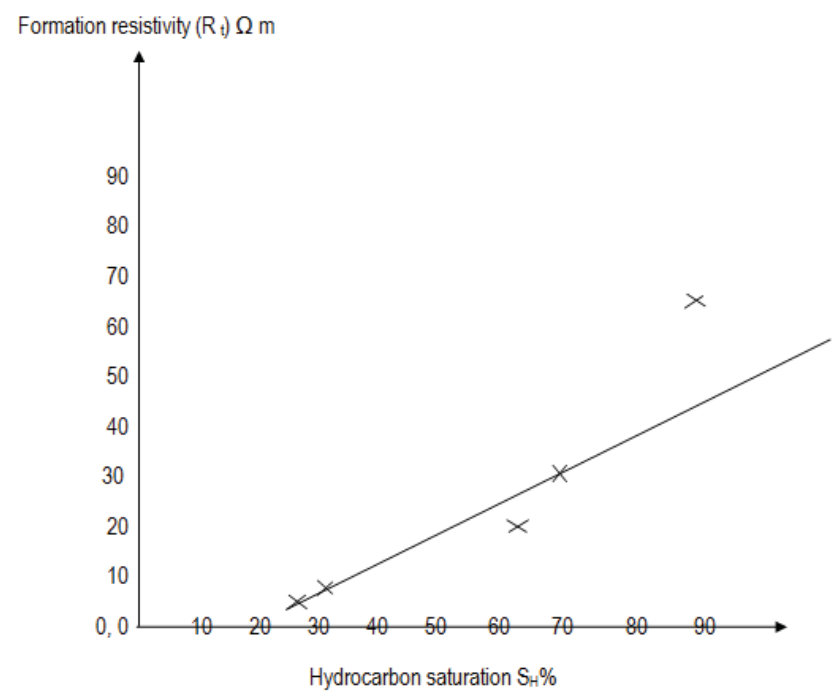

\section{References}

Archie 1942: The electrical resistivity log as an aid in developing some reservoir characteristics. Retrieved from en.wiklipedia. org/wiki/archies law 14 September, 2013

(David F, Allen 2009): Method for quantifying resistivity and hydrocarbon saturation in thin bed formation Published 2009 - 02- 12

Invan S 2012: The adaptive technique of hydrocarbon saturation determination Middle East Geosciences Conference and Exhibition, 4 -7 March 20012, Manama, Bahrain.

Prasodjo and Y. Sallam 2006 : Estimating water saturation with a volume measurement (Extracted from www.woroldio.com on 9/13/2013)

Roland Chemali 2012: Computing hydrocarbon saturation in laminated reservoir (Soraya Betan court 2010): Method of integrating reservoir charge modeling and down hole analysis. Published 2010 09- 09. 
